\title{
Elicitor Mixtures Significantly Increase Bioactive Compounds, Antioxidant Activity, and Quality Parameters in Sweet Bell Pepper
}

\author{
Lina Garcia-Mier, Sandra Neli Jimenez-Garcia, Ramon Gerardo Guevara-González, \\ Ana Angelica Feregrino-Perez, Luis Miguel Contreras-Medina, and Irineo Torres-Pacheco
}

\author{
Biosystems Engineering Group, Biosystems Laboratory, Division of Graduate Studies, Faculty of Engineering, \\ Autonomous University of Queretaro, Cerro de las Campanas, S/N, Colonia Las Campanas, C.U., \\ 76010 Santiago de Querétaro, QRO, Mexico \\ Correspondence should be addressed to Irineo Torres-Pacheco; irineo.torres@uaq.mx
}

Received 8 January 2015; Revised 27 May 2015; Accepted 1 June 2015

Academic Editor: Surya P. Gupta

Copyright (C) 2015 Lina Garcia-Mier et al. This is an open access article distributed under the Creative Commons Attribution License, which permits unrestricted use, distribution, and reproduction in any medium, provided the original work is properly cited.

\begin{abstract}
Sweet bell peppers are greatly appreciated for their taste, color, pungency, and aroma. Additionally, they are good sources of bioactive compounds with antioxidant activity, which can be improved by the use of elicitors. Elicitors act as metabolite-inducing factors (MIF) by mimic stress conditions. Since plants rarely experience a single stress condition one by one but are more likely to be exposed to simultaneous stresses, it is important to evaluate the effect of elicitors on plant secondary metabolism as mixtures. Jasmonic acid (JA), hydrogen peroxide (HP), and chitosan $(\mathrm{CH})$ were applied to fruits and plants of bell pepper as mixtures. Bioactive compounds, antioxidant activity, and quality parameters were evaluated. The assessed elicitor cocktail leads to an increase in the variables evaluated $(P \leq 0.05)$ when applied to mature fruits after harvest, whereas the lowest values were observed in the treatment applied to immature fruits. Therefore, the application of the elicitor cocktail to harvested mature fruits is recommended in order to improve bioactive compounds and the antioxidant activity of sweet bell peppers.
\end{abstract}

\section{Introduction}

Pepper is an important agricultural crop, not only because of its economic significance, but also for its role in food for its unique flavor and aroma. Sweet bell peppers are being widely studied as a result of their high content of bioactive compounds with antioxidant activity such as carotenoids, vitamin C, and phenolic compounds [1]. These compounds in food are important health-protecting factors and their presence depends on cultivar, maturity, growing conditions, and postharvest manipulation [2]. A number of studies reveal that there is an inverse correlation between the ingestion of food rich in bioactive compounds, which can be the result of secondary metabolism, and chronic diseases; hence it is of great interest to raise their presence in foods. Secondary metabolites play an important role in the adaptation of plant to stress conditions; for this reason, elicitors that simulate different biotic and abiotic stress conditions trigger the plant biochemical system towards the increasing of secondary metabolites [3]. This suggests that treating the plants with elicitors could be a strategy of low risk to enhance the presence of these compounds in the plant. A plethora of substances, such as jasmonates, salicylates, and carbohydrates (e.g., chitosan), display elicitor activity. Since elicitors could induce the production not only of secondary, but also of primary metabolites $[4,5]$, it is suggested to call them metabolite-inducing factors (MIF). Although it is reported that the synthesis of secondary metabolites can be induced in plants by the application of MIF [6,7] and their effect depends on factors, such as MIF concentration and time of application [8], scarce information is available related to the phytochemical content and antioxidant activity of sweet bell peppers as a result of the application of MIF as cocktails (mixture of three elicitors, in this work) to different parts of the plant (leaves, fruits, and whole plant). 
In elicitation treatments commonly a unique elicitor is used; however, plants are under the influence of multiple stress factors; therefore it is important not only to study the effect of one elicitor but to study the effect of a cocktail of them, since it has been established that cross talk between signals could allow fine-tuning of defense responses in local and systemic tissue. Jasmonic acid, hydrogen peroxide, and chitosan are compounds closely related to stress response [9-11]. Also, to our knowledge no detailed information is available related to the effect of elicitors-mixtures applied to sweet bell pepper plants and mature and immature fruits of sweet bell pepper. Besides, with the frame of xenohormesis [12], flavonoids, tannins, and carotenoids exert health benefits to humans due to their antioxidant capacity related with their ability for scavenging reactive oxidant species [1,13]. Keeping this in view, the objective of the present study was to evaluate the production of some bioactive compounds, antioxidant capacity, and quality parameters as result of MIF cocktail (jasmonic acid, hydrogen peroxide, and chitosan) applied to plants and fruits of sweet bell pepper.

\section{Materials and Methods}

2.1. Plant Material and Growth Conditions. Sweet bell pepper seeds (Capsicum annum L. cv. Fascinato) were purchased from Syngenta (Rogers) (Basel, Switzerland). They were disinfected using $1 \mathrm{~mL} \cdot \mathrm{L}^{-1}$ EcoCitro (Ecología Agroindustrial S.A. de C.V., Santiago de Querétaro, QRO, México). The seeds were sowed in 160 cavities' polystyrene tray, with vermiculite and peat moss, and placed in a small germination chamber $\left(25^{\circ} \mathrm{C}, 70 \% \mathrm{RH}\right)$ until germination. Seventyseven days postgermination, seedlings were transplanted into coconut fiber in a greenhouse $\left(528 \mathrm{~m}^{2}\right)$ with a plant density of 4 plants $\cdot \mathrm{m}^{-2}$. The greenhouse was located in Amazcala, Querétaro state, México (longitude of $100^{\circ} 16^{\prime} \mathrm{W}$; latitude, $20^{\circ} 42^{\prime} \mathrm{N}$; altitude, $1920 \mathrm{~m}$ ). Morphologically uniform seedlings were selected. Drip irrigation was used with plastic hoses of $16 \mathrm{~mm}$ diameter and drippers emitting $4 \mathrm{~L} \cdot \mathrm{h}^{-1}$. Watering was according to phenological stage of the plants, with daily applications of $400 \mathrm{~mL}$ water per plant in recently transplanted plants, increasing gradually to $1300 \mathrm{~mL}$ per plant at 100 days posttransplanting. The nutrition solution used was modified during the crop. Plants were grown in coconut fiber under natural lighting with day and night temperatures varying between $37^{\circ} \mathrm{C}$ and $13^{\circ} \mathrm{C}$. Relative humidity was $50-$ $55 \% \mathrm{RH}$, and radiation was $743 \pm 72 \mathrm{~W} \cdot \mathrm{m}^{-2}$ during the study. The experiment was carried out using a completely randomized block design with three replicates. Each replicate consisted of 50 plants, giving a total of 10 per treatment. Plants were distributed throughout the greenhouse in three lanes; each lane included all treatments. The distance between lanes was $1.5 \mathrm{~m}$; within each lane there was a distance of $30 \mathrm{~cm}$ between treatments.

2.2. Application of Elicitor Mixtures. Jasmonic acid (JA), hydrogen peroxide $(\mathrm{HP})$, and chitosan $(\mathrm{CH})$ were purchased from Sigma-Aldrich (St. Louis, MO, USA), Degasa (Jiutepec, Morelos, Mexico), and Agrinos México, S.A. de C.V.
(Navojoa, Sonora, Mexico), respectively. The HP (27 mM), JA $(1 \mu \mathrm{M})$, and $\mathrm{CH}(0.75 \%)$ concentrations were selected based on previous reports $[10,14]$. The JA stock solution $(130 \mu \mathrm{M})$ was prepared by dissolving the elicitor in $3 \mathrm{~mL}$ of ethanol and afored to $1 \mathrm{~L}$ with distilled water. The HP, JA, and $\mathrm{CH}$ solutions were prepared as water dilutions. The elicitor mixture was applied to plants and to harvested fruits with the intention to find if there is a differential production of secondary metabolites according to application method and what method results in a major production of them. When applied to plants, the mixture of the three inducers was foliar or whole plant sprayed to runoff fortnightly. For harvested fruits, the elicitor mixture was applied once to immature and mature fruits. Control plants were sprayed with water.

2.3. Fruit Samples. Peppers were harvested at full-red stage, except fruits from the immature treatment that were harvested at green stage of maturity. Samples were cut into slices (seeds were discarded), frozen with nitrogen, and stored at $-80^{\circ} \mathrm{C}$ until their analysis. Each sample consisted of $150 \mathrm{~g}$.

2.4. Extract Preparation. Extractions of phenolic compounds were performed by placing $1 \mathrm{~g}$ (PRACTUM 224-1S; Sartorius, Göttingen, Germany) of fresh sample in a $50 \mathrm{~mL}$ tube and mixing with $10 \mathrm{~mL}$ of methanol [15]. The tubes were protected from light and shaken (Orbit 1000 model S2030-1000; Labnet, Woodbridge, NJ, USA) at $200 \mathrm{rpm}$ for $24 \mathrm{~h}$ at $25^{\circ} \mathrm{C}$. After incubation, the samples were centrifuged (Sorvall Biofuge Primo R model 75005448; Thermo Scientific, Osterode, Germany) at $6,793 \times \mathrm{g}$ for $10 \mathrm{~min}$. Aliquots of the supernatant were taken for the assays. Carotenoid extraction was made as follows: $2.5 \mathrm{~g}$ of fresh sample was placed in a $50 \mathrm{~mL}$ tube and mixed with $20 \mathrm{~mL}$ of hexane, acetone, and ethanol in a proportion of $5: 2.5: 2.5$. The tubes were protected from light and shaken (Orbit 1000 model S2030-1000; Labnet, Woodbridge, NJ, USA) at $200 \mathrm{rpm}$ for $24 \mathrm{~h}$ at $25^{\circ} \mathrm{C}$. After incubation, the samples were centrifuged (Velocity 14R; Dynamica, Salzburg, Austria) at $16,211 \times \mathrm{g}$ for $10 \mathrm{~min}$.

2.5. Quantification of Condensed Tannins. Condensed tannins (CT) expressed as milligrams of $(+)$-catechin equivalents per gram of fresh sample $\left(\mathrm{mg}\right.$ of $\mathrm{CT} \cdot \mathrm{g}^{-1}$ ) were quantified according to the procedure reported by Feregrino-Pérez et al. [16]. Briefly, $200 \mu \mathrm{L}$ of vanillin reagent (1\% vanillin, $8 \% \mathrm{HCl}$ in methanol) was added to $50 \mu \mathrm{L}$ of methanolic extract and placed in a 96-well plate; each sample was tested in triplicate. Condensed tannins were quantified at $492 \mathrm{~nm}$ in a microplate reader (Multiskan Go model 51119300; Thermo Scientific, Vantaa, Finland) using (+)-catechin (up to $0.1 \mathrm{mg} \cdot \mathrm{mL}^{-1}$ ) as a reference standard. A blank sample was prepared by subjecting the original extract to the same conditions of reaction without the vanillin reagent.

2.6. Quantification of Flavonoids. Briefly, the method for the determination of flavonoid $(\mathrm{F})$ content consisted of mixing $50 \mu \mathrm{L}$ of the methanolic extract with $180 \mu \mathrm{L}$ of distilled water and $20 \mu \mathrm{L}$ of a solution 2 -aminoethyldiphenylborate $1 \%$ in a 96-well plate [17]. The absorbance of the solution was 
monitored at $404 \mathrm{~nm}$ with a microplate reader (Multiskan Go model 51119300; Thermo Scientific, Vantaa, Finland). A rutin standard was prepared in methanol. Extract absorption was compared with that of a rutin standard curve (up to $\left.2 \mu \mathrm{g} \cdot \mathrm{mL}^{-1}\right)$. Flavonoid content was expressed as micrograms of rutin equivalent per gram of fresh sample ( $\mu \mathrm{g}$ of F.g $\left.{ }^{-1}\right)$.

2.7. Quantification of Total Carotenoids. Total carotenoids (TC) were determined as follows. Briefly, $200 \mu \mathrm{L}$ of the carotenoid extract was diluted with $2.8 \mathrm{~mL}$ of the extract mixture (hexane, acetone, and ethanol) and read in a spectrophotometer (Multiskan Go model 51119300; Thermo Scientific, Vantaa, Finland) in scanning mode (400-750 nm). Total carotenoids were estimated by taking the maximum absorbance and expressed as mg of $\beta$-carotene equivalent per one hundred $\mathrm{g}$ of fresh sample ( $\mathrm{mg}$ of TC $\cdot 100 \mathrm{~g}^{-1}$ ) according to the following, where $A_{\max }$ is maximum absorbance, $L$ is cell path $(1 \mathrm{~cm}), f$ is dilution factor, and absorptivity coefficient is $250 \mathrm{~L} \cdot \mathrm{g}^{-1} \cdot \mathrm{cm}^{-1}$ :

$$
\text { Total carotenoids }\left(\mathrm{mg} \cdot 100 \mathrm{~g}^{-1}\right)=\frac{A_{\max } \times 100 \times f}{250 \times L} \text {. }
$$

2.8. Antioxidant Activity by 1,1-Diphenyl-2-Picrylhydrazyl $(D P P H)$ Radical Inhibition Assay. Radical scavenging activity (RSA) was determined using stable radical DPPH method using the method of Brand-Williams et al. [18] modified by Fukumoto and Mazza [19]. The assay was performed following the next procedure. All reactions were conducted in 96-well microplates. Aliquot $(20 \mu \mathrm{L})$ of methanolic extracts was mixed with $100 \mu \mathrm{M}$ of DPPH $(200 \mu \mathrm{L})$ in methanol. A control and a blank were used. After 30 minutes' incubation at ambient temperature in darkness, absorbance was recorded at $515 \mathrm{~nm}$ in a microplate reader (Multiskan Go model 51119300; Thermo Scientific, Vantaa, Finland). Calibration curve with Trolox (up to $50 \mu \mathrm{M}$ ) was prepared. The antioxidant activity was reported in $\mu$ moles of Trolox equivalent per gram of fresh sample $\left(\mu \mathrm{mol}\right.$ of TE$\left.\cdot \mathrm{g}^{-1}\right)$.

2.9. Quantification of Carotenoids by HPLC. Carotenoids and tocopherols were extracted as it is next described. Briefly, $2 \mathrm{~g}$ of tissue was extracted with $500 \mu \mathrm{L}$ of ethanol containing $0.1 \%$ butylated hydroxytoluene (BHT). After shaking, samples were heated to $80^{\circ} \mathrm{C}$ for $10 \mathrm{~min}$. Then, $10 \mu \mathrm{L}$ of $\mathrm{KOH} 80 \%$ was added. After shaking, samples were heated again to $80^{\circ} \mathrm{C}$ for $10 \mathrm{~min}$. Samples were incubated on ice for $10 \mathrm{~min}$ and, then, $500 \mu \mathrm{L}$ of cold deionized water was added. Afterwards, $500 \mu \mathrm{L}$ of hexane was added and shaken. Samples were centrifuged at $13,000 \mathrm{rpm}$ for $5 \mathrm{~min}$ at $4^{\circ} \mathrm{C}$. Samples were reextracted with hexane and after centrifugation, the up layer was taken and it was transferred to a clean tube. The extract was dried under a nitrogen flow; tubes were closed and kept at $20^{\circ} \mathrm{C}$ until high-pressure liquid chromatography (HPLC) analysis. Samples were prepared for HPLC by dissolving the dried residues in $200 \mu \mathrm{L}$ of ethanol containing $0.1 \%$ BHT. HPLC analysis was performed using Agilent Eclipse Plus C18 column $(4.6 \times 150 \mathrm{~mm}, 5 \mu \mathrm{m})$ maintained at $30^{\circ} \mathrm{C}$. The mobile phase used was methanol and acetonitrile $(45: 55, v / v)$. Flow rate of $1 \mathrm{~mL} \cdot \mathrm{min}^{-1}$ was used until minute 14 ; then, the flow rate changed to $2 \mathrm{~mL} \cdot \mathrm{min}^{-1}$. The injection volume was $20 \mu \mathrm{L}$. The analysis lasted 35 minutes. Chromatography was carried out on Agilent series 1200 system consisting of a quaternary pump, photo diode array (PDA) detector. Data were collected and analyzed using the Agilent Chemstation software supplied. Carotenoids were detected by setting the PDA to 290 and $450 \mathrm{~nm}$. Quantitative determination of compounds was conducted by comparison with dose-response curves constructed from standards (lutein, zeaxanthin, $\alpha$-tocopherol, $\beta$ cryptoxanthin, lycopene, and $\beta$-carotene). Limit of detection and limit of quantification expressed as $\mu \mathrm{g} \mathrm{mL} L^{-1}$ were 0.536 and 0.893 (lutein); 0.951 and 1.585 (zeaxantin); 0.242 and 0.404, ( $\alpha$-tocopherol); 0.496 and 0.827 ( $\beta$-cryptoxanthin); 0.104 and 0.174 (lycopene); and 1.364 and 2.274 ( $\beta$-carotene). Each value was the mean of three replicates.

2.10. Determination of Soluble Solids and $p H$. A slice of pepper was squeezed to get the clear juice. It was placed onto the refractometer prism plate to get the lecture. The percent of soluble solids was determined using a temperature correcting refractometer (PAL-1 model 3810; Atago, Tokio, Japan) and results are expressed as ${ }^{\circ} \mathrm{Brix}$. The $\mathrm{pH}$ determinations were made using a digital $\mathrm{pH}$ meter (Educational model HI208; Hanna, Woonsocket, RI, USA) calibrated with $\mathrm{pH} 4$ and 7 buffers. For $\mathrm{pH}$ determinations $20 \mathrm{~g}$ of fresh samples was dissolved in $20 \mathrm{~mL}$ of distilled water.

2.11. Statistical Analysis. Data were subjected to analysis of variance (ANOVA) followed by Tukey's test (with $P \leq 0.05$ ) by JMP (SAS Institute Inc., Cary, NC, USA).

\section{Results and Discussion}

Flavonoids, condensed tannins, and carotenoids as well as antioxidant activity were analyzed in pepper fruits after the application of MIF cocktails by spectrophotometric methods. An amount of reports indicates that these compounds are involved in the prevention of nontransmissible chronic diseases by means of their antioxidant activity $[1,13]$. Quantification of individual carotenoids was also carried out by HPLC. The elicitor mixture sprayed to the mature fruit significantly increased the content of these metabolites. It is believed that it could be a synergism in the application of the mixture of elicitors that activate signal transduction pathways that produce secondary signals produced by plants $[20,21]$. Defense responses regulated by jasmonates could also involve hydrogen peroxide [11]; besides chitosan stimulates the production not only of hydrogen peroxide but also of jasmonic acid, signal molecules related to defense regulation [22]. Also, Zhang and Memelink [23] mention that there exists a positive feedback mechanism for jasmonate biosynthesis in which jasmonates stimulate their own production. Wasternack and Hause [20] mention that a principle of signaling is related to a generation of signals that is divergent but a transduction that is convergent, but a divergent response could also occur since here it is also established that the activation of individual sets of genes takes place in a spatial and temporal manner. 
TABLE 1: Flavonoids, condensed tannins, and carotenoids composition of sweet bell pepper as a result of MIF application* .

\begin{tabular}{|c|c|c|c|}
\hline MIF application & Flavonoids $\left(\mu \mathrm{g}\right.$ of $\left.\mathrm{F} \cdot \mathrm{g}^{-1}\right)$ & Condensed tannins (mg of CT $\cdot \mathrm{g}^{-1}$ ) & Carotenoids (mg TC $\left.\cdot 100 \mathrm{~g}^{-1}\right)$ \\
\hline Control & $279.00 \pm 8.66^{\mathrm{b}}$ & $5.05 \pm 0.11^{\mathrm{b}}$ & $33.09 \pm 2.24^{\mathrm{ab}}$ \\
\hline Foliar & $276.60 \pm 9.43^{\mathrm{b}}$ & $5.16 \pm 0.13^{\mathrm{b}}$ & $22.99 \pm 2.40^{\mathrm{b}}$ \\
\hline Whole plant & $244.60 \pm 14.99^{\mathrm{b}}$ & $4.60 \pm 0.41^{\mathrm{b}}$ & $21.40 \pm 4.63^{\mathrm{bc}}$ \\
\hline Immature fruit & $168.80 \pm 8.98^{c}$ & $0.47 \pm 0.12^{\mathrm{c}}$ & $7.05 \pm 2.20^{c}$ \\
\hline Mature fruit & $441.14 \pm 16.95^{\mathrm{a}}$ & $9.32 \pm 0.44^{\mathrm{a}}$ & $44.42 \pm 5.00^{\mathrm{a}}$ \\
\hline
\end{tabular}

* Each value is the mean of three replicates \pm standard error. Different letters in each column express significant difference $P \leq 0.05$ by Tukey's test.

The minor content of the metabolites evaluated was found in the fruit sprayed in the immature state. These results suggest that sprinkling peppers with the elicitor mixture when these have reached maturity augments the content of secondary metabolites. The latter is probably because, at mature state, fruits have fully developed their metabolic routes and the production of such metabolites is arranged in one organ and not in the whole plant as a result of translocation effects [24]. It has been indicated that separate application of jasmonates, hydrogen peroxide, and chitosan enhances the production of plant secondary metabolites $[10,11,25]$. In this way, Heredia and Cisneros-Zevallos [7] found that the phenolic content of lettuce, green beans, and plum is induced by the application of methyl jasmonate. Also, Tierranegra-García et al. [14] showed an inversely proportional relation between phenolics and flavonoids contents with pill-bugs mortality in lettuce. Bayoumi [26] found that hydrogen peroxide treatments significantly increased ascorbic acid content and the activity of the antioxidant enzymes. Pérez-Balibrea et al. [27] reported that the use of chitosan in broccoli induced increases of $54 \%$ of vitamin C.

3.1. Flavonoids and Condensed Tannins. Peppers contain phytochemicals that can contribute to antioxidant activity, such as phenolic compounds. Flavonoids have been identified as the main phenolic compounds in pepper. Ruiz-García and Gómez-Plaza [28] expressed that elicitor application can be a strategy to raise plants with enhanced polyphenol content. Indeed, it is mentioned that plants produce defensive compounds depending on the type of attack. The large increase of the content of total phenolic compounds, flavonoids (58.1\%) and condensed tannins (84.6\%), occurred in mature fruits (Table 1). The minor content happened in fruits where the elicitor mixture was applied at the immature state. An increase of phenolic compounds with maturation has been previously described [29]. Thus, elicitor mixture affected phenolic compound content, since this content was significantly different in treated peppers than in controls. A positive relation between condensed tannins and flavonoid content was found $\left(r^{2}=0.93\right)$. It was an expected result since tannins belong to the flavonoid group. The elicitor mixture applied either in foliar manner or to the whole plant resulted in similar phenolic content compared to control (Table 1). This behavior could indicate that when the elicitor mixture is applied to the whole plant or in a foliar manner, secondary metabolites could be produced or translocated via xylem to other plants' parts rather than in the traditional edible part of the plant (fruits) $[20,30]$. Further research must be done in order to confirm this statement.

3.2. Carotenoids. Carotenoids are an integral part of the human diet and there is increasing evidence that they are involved in the observed beneficial effects on the prevention of several chronic diseases. Therefore great efforts are being made in order to increase their presence in foods which include genetic manipulation and the use of promoting substances [31, 32]. For example, Raman and Ravi [33] studied the influence of phytohormones and salicylic and methyl jasmonate on the antioxidant systems in Haematococcus pluvialis and concluded that these phytohormones could be used for elicitation of secondary carotenoid production. The concentration and composition of carotenoids determined fruit color. The quantitative analysis of carotenoids revealed that total carotenoid content increased in mature fruits treated with the elicitor mixture compared with the control not subjected to the elicitor mixture (Table 1). The total concentration of the carotenoids detected in sprayed mature fruits was approximately $34.2 \%$ greater than that in control fruits. Data showed that foliar and whole plant treatment displayed minor differences with control; however, it was found that control has a greater amount of carotenoids. Thus, carotenoid concentration was decreased by nearly $35.3 \%$ and $30.5 \%$, respectively, in plants that were wholly and foliarly sprayed with the elicitor mixture compared with those plants that were sprayed with water. These results suggest that in foliarly and wholly sprayed plant other substances rather than carotenoids are produced as a result of elicitor mixture applications or their production is achieved in other plant organs rather than fruits. As expected, sprayed immature fruits had the lowest carotenoid content (Table 1). The intense red color in pepper is due to carotenoid pigments that are synthesized mainly during fruit ripening [34]. The concentration of carotenoids increases as the peppers reached maturity [35]. The total carotenoid concentrations are in the range reported by other authors for mature and immature bell peppers $[35,36]$. The spectrophotometric assay for total carotenoid determination allows estimating the total carotenoid considering the $\beta$-carotene to be reference; however, in order to estimate individual carotenoids it is necessary to perform chromatographic analysis. This is important since studies reveal that carotenoids have different bioaccessibility and bioavailability as well as different bioactivity [37]. Chromatographic analysis indicated that two of the carotenoids evaluated are higher for the treatment sprayed to mature fruit. 
TABLE 2: Carotenoid profile of sweet bell pepper as a result of MIF application* .

\begin{tabular}{|c|c|c|c|c|c|c|}
\hline MIF application & $\begin{array}{c}\text { Lutein } \\
\left(\mu \mathrm{g} \cdot \mathrm{g}^{-1}\right)\end{array}$ & $\begin{array}{c}\text { Zeaxanthin } \\
\left(\mu \mathrm{g} \cdot \mathrm{g}^{-1}\right)\end{array}$ & $\begin{array}{c}\alpha \text {-tocopherol } \\
\left(\mu \mathrm{g} \cdot \mathrm{g}^{-1}\right)\end{array}$ & $\begin{array}{c}\beta \text {-cryptoxanthin } \\
\left(\mu \mathrm{g} \cdot \mathrm{g}^{-1}\right)\end{array}$ & $\begin{array}{c}\text { Lycopene } \\
\left(\mu \mathrm{g} \cdot \mathrm{g}^{-1}\right)\end{array}$ & $\begin{array}{c}\beta \text {-carotene } \\
\left(\mu \mathrm{g} \cdot \mathrm{g}^{-1}\right)\end{array}$ \\
\hline Control & $3.945 \pm 0.013^{b}$ & - & $4.874 \pm 0.229^{\mathrm{ab}}$ & - & $5.644 \pm 0.450^{\mathrm{b}}$ & - \\
\hline Foliar & $3.969 \pm 0.025^{\mathrm{b}}$ & - & $5.796 \pm 0.930^{\mathrm{a}}$ & - & $2.670 \pm 0.842^{\mathrm{b}}$ & - \\
\hline Whole plant & $3.834 \pm 0.029^{c}$ & - & $2.953 \pm 0.400^{b c}$ & - & $1.646 \pm 0.301^{\mathrm{b}}$ & - \\
\hline Immature fruit & $3.832 \pm 0.014^{c}$ & - & $2.069 \pm 0.421^{c}$ & - & - & - \\
\hline Mature fruit & $4.253 \pm 0.028^{\mathrm{a}}$ & - & $6.164 \pm 0.247^{\mathrm{a}}$ & - & $13.447 \pm 1.629^{\mathrm{a}}$ & $6.726 \pm 0.055$ \\
\hline
\end{tabular}

* Each value is the mean of three replicates \pm standard error. Different letters in each column express significant difference $P \leq 0.05$ by Tukey's test.

TABLE 3: Radical scavenging activity of sweet bell pepper as a result of MIF application*.

\begin{tabular}{lc}
\hline MIF application & $\begin{array}{c}\text { Antioxidant } \\
\text { activity } \\
\left(\mu \mathrm{mol} \mathrm{of} \mathrm{TE} \cdot \mathrm{g}^{-1}\right)\end{array}$ \\
\hline Control & $5.17 \pm 0.38^{\mathrm{a}}$ \\
Foliar & $4.09 \pm 0.60^{\mathrm{ab}}$ \\
Whole plant & $4.33 \pm 0.27^{\mathrm{ab}}$ \\
Immature fruit & $2.72 \pm 0.20^{\mathrm{b}}$ \\
Mature fruit & $5.47 \pm 0.62^{\mathrm{a}}$ \\
\hline
\end{tabular}

${ }^{*}$ Each value is the mean of three replicates \pm standard error. Different letters in each column express significant difference $P \leq 0.05$ by Tukey's test.

For this treatment, concentrations of lutein and lycopene were significantly different when compared with control $(P \leq 0.05)$, but no significant differences with control were found for $\alpha$-tocopherol. Zeaxanthin and $\beta$-cryptoxanthin were not quantifiable. $\beta$-carotene was quantifiable in the mature treatment (Table 2). This is relevant since it is the more potent provitamin A carotenoid [38]. Conversely, any of the other treatments accumulate detectable levels of this carotenoid. Lutein, as mentioned by Wahyuni et al. [39], is usually detected in green peppers. Yahia and Ornelas Paz [38] commented that it was found in humans that lutein is more bioavailable than $\beta$-carotene. Its activity in the prevention of age-related macular degeneration is well known [40]. Lutein, lycopene, and $\beta$-cryptoxanthin represent almost $90 \%$ of carotenoids in human diet. The first two were enhanced by the mixture of elicitors applied to mature fruit.

3.3. Antioxidant Activity. Antioxidant capacity is an important reference to establish the health function of a food product. This test is related to the ability to prevent freeradical mediated oxidation of the substrate when present in low concentration. In the present study, antioxidant activity was measured by the free radical ( $\left.\mathrm{DPPH}^{*}\right)$ scavenging assay. DPPH assay has been commonly used to assess antioxidant activity. DPPH is based on free radical scavenging activity. Antioxidant activities ranged from 2.72 to $5.47 \mu \mathrm{mol} \mathrm{TE} \cdot \mathrm{g}^{-1}$ (Table 3). The study revealed that antioxidant activity in mature treated fruits is higher (5.8\%) when elicitor mixture is applied. DPPH assay was developed as an accurate method for antioxidant studies in fruit and vegetable [41]; however, it will be valuable to perform other antioxidant assays (e.g., TBA, $\beta$-carotene bleaching assay) in order to test antioxidant activity with methods that are associated with lipid peroxidation instead of radical scavenging to estimate possible significant differences. Foliarly and wholly sprayed plants displayed similar antioxidant activity, whereas immature treated fruit exhibited the lowest activity. This disparity could be related to differences either in potency or in the concentration of bioactive substances (i.e., flavonoids, tannins, and carotenoids). Sweet bell peppers have a great diversity of phenolic compounds, and the profile and/or proportions within the profile of these compounds may change; therefore differences in these profiles may result in changes in antioxidant activity. Change in antioxidant activity as a result of elicitor has been reported as well as differences in these parameters between mature and immature fruits [42]. Literature reports concerned with the correlation between antioxidant activity and reducing substances varied widely. Some indicated that there is a strong positive relationship while others indicated a weak one $[29,43]$. In this study, a high correlation between these variables was not found (flavonoids $r^{2}=0.21$, condensed tannins $r^{2}=0.24$, and carotenoids $r^{2}=0.11$ ). It could be attributed because antioxidant activity is not just a relation of quantity but a relation of quality of the content of reducing substances [38].

3.4. Soluble Solids and $p H$. $\mathrm{pH}$ values remain similar to that of the control (4.79) for elicitor mixture sprayed foliarly and to the whole plant and mature fruits $(4.80-5.02)$. Differences were observed for fruits sprayed at the immature state (5.34). Previous studies have found increase in acids, especially ascorbic acid, when peppers reach maturity [44], while others have found a decrease [45]. Levels of soluble solids were higher in mature peppers (9.06), almost 62\% higher than control (Figure 1). Soluble solids for treatment sprinkled to leaves, whole plants, and immature fruits are 6.16, 5.10, and 5.76 Brix, respectively. This variable is scarcely affected when these treatments are applied. Higher ${ }^{\circ}$ Brix values can influence the perceived sweetness of the peppers. According to Luning et al. [46], fructose, glucose, total sugar, and dry matter content were related to the attribute sweetness while undissociated ascorbic and dissociated citric acid are related to sourness.

\section{Conclusion}

Elicitor mixture, evaluated in this work, induced an increase in bioactive compounds in mature sweet bell peppers which 


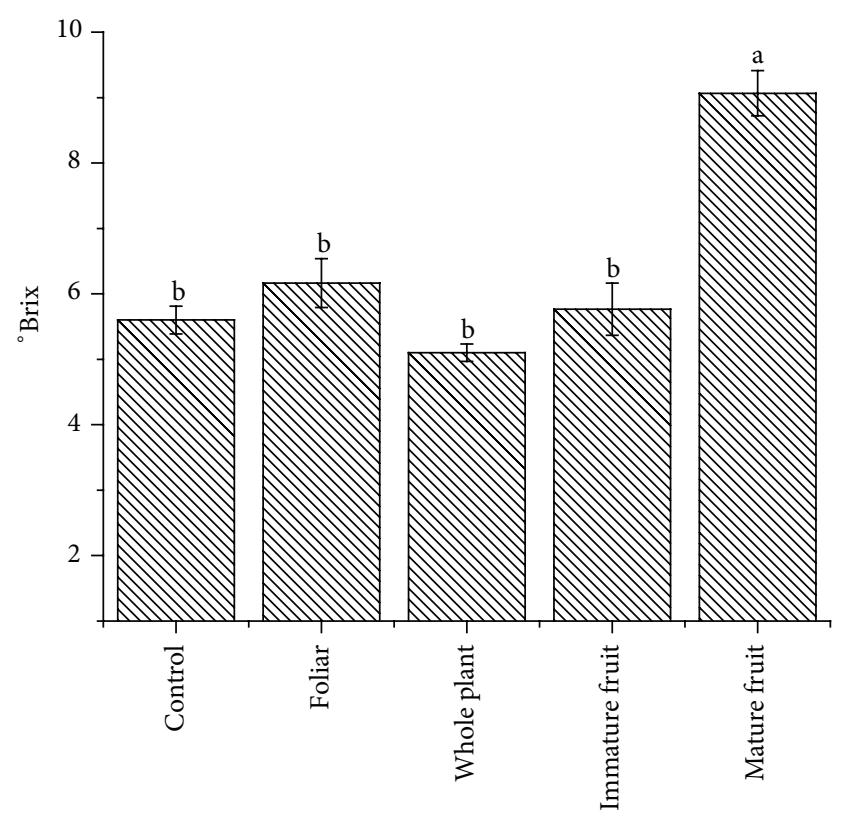

Treatment

FIGURE $1:{ }^{\circ}$ Brix of different MIF cocktails treatments. The same letter above the bars indicates no significant difference $(P \leq 0.05)$. Each bar is the mean of three replicates \pm standard error.

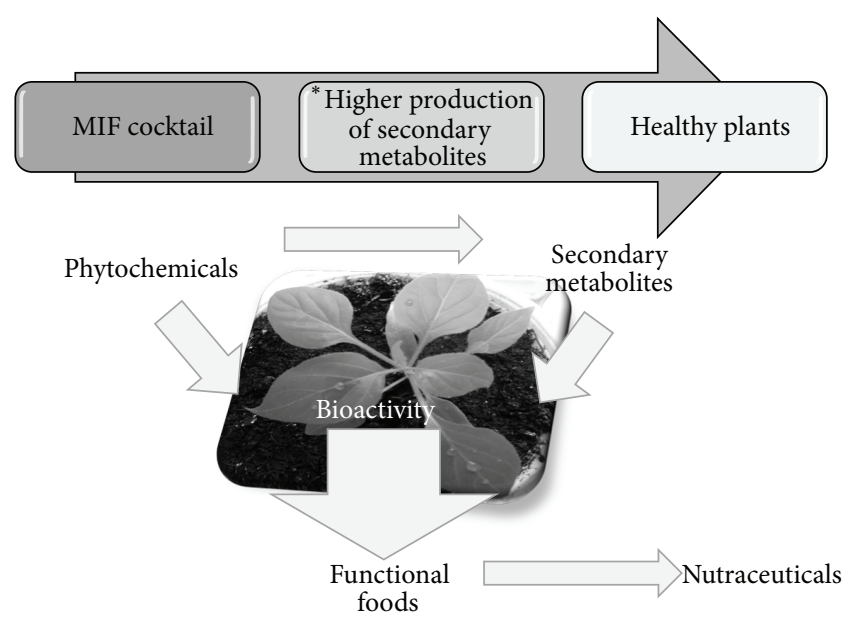

FIgURE 2: Suggested implications of the application of the MIF cocktail.

could suggest a concomitant increase in functional properties. The use of elicitor mixtures might be a useful strategy to increase phenolic and carotenoid content in sweet bell pepper. A general positive effect of elicitor mixtures applied foliarly and to the whole plant was not found. It could be advisable to apply elicitor mixtures at the full-mature red stage to achieve the greatest benefit of their consumption in terms of health promoting activity as well as low cost for plant growth and development. Further research related to the regulation of secondary metabolism is needed to achieve peppers as enriched dietary sources of bioactive compounds (Figure 2).

\section{Conflict of Interests}

The authors declare no conflict of interests.

\section{Acknowledgments}

The authors express their thanks to CONACYT (Grant 268854), FORDECYT (193512), and FOMIX-Querétaro (192844) for their support to this work. Special thanks are extended to the Translation Edition Office of UAQ for technical review of the English paper and to Ismael Urrutia-Anaya and Hugo Jesús Mendoza-Landeros for their assistance with the greenhouse work. Thanks also are due to Elvia Olvera-Olvera for her guidance with the crop.

\section{References}

[1] D. Hervert-Hernández, S. G. Sáyago-Ayerdi, and I. Goñi, "Bioactive compounds of four hot pepper varieties (Capsicum annuum L.), antioxidant capacity, and intestinal bioaccessibility," Journal of Agricultural and Food Chemistry, vol. 58, no. 6, pp. 3399-3406, 2010.

[2] A. W. Chassy, L. Bui, E. N. C. Renaud, M. Van Horn, and A. E. Mitchell, "Three-year comparison of the content of antioxidant microconstituents and several quality characteristics in organic and conventionally managed tomatoes and bell peppers," Journal of Agricultural and Food Chemistry, vol. 54, no. 21, pp. 82448252, 2006.

[3] J. Zhao, L. C. Davis, and R. Verpoorte, "Elicitor signal transduction leading to production of plant secondary metabolites," Biotechnology Advances, vol. 23, no. 4, pp. 283-333, 2005.

[4] C. D. Broeckling, D. V. Huhman, M. A. Farag et al., "Metabolic profiling of Medicago truncatula cell cultures reveals the effects of biotic and abiotic elicitors on metabolism," Journal of Experimental Botany, vol. 56, no. 410, pp. 323-336, 2005.

[5] Y. Wang and M. Frei, "Stressed food-the impact of abiotic environmental stresses on crop quality," Agriculture, Ecosystems \& Environment, vol. 141, no. 3-4, pp. 271-286, 2011.

[6] F. Bi, S. Iqbal, M. Arman, A. Ali, and M.-U. Hassan, "Carrageenan as an elicitor of induced secondary metabolites and its effects on various growth characters of chickpea and maize plants," Journal of Saudi Chemical Society, vol. 15, no. 3, pp. 269$273,2011$.

[7] J. B. Heredia and L. Cisneros-Zevallos, "The effects of exogenous ethylene and methyl jasmonate on the accumulation of phenolic antioxidants in selected whole and wounded fresh produce," Food Chemistry, vol. 115, no. 4, pp. 1500-1508, 2009.

[8] G.-T. Jeong and D.-H. Park, "Enhancement of growth and secondary metabolite biosynthesis: effect of elicitors derived from plants and insects," Biotechnology and Bioprocess Engineering, vol. 10, no. 1, pp. 73-77, 2005.

[9] B.-E. Amborabé, J. Bonmort, P. Fleurat-Lessard, and G. Roblin, "Early events induced by chitosan on plant cells," Journal of Experimental Botany, vol. 59, no. 9, pp. 2317-2324, 2008.

[10] L. Mejía-Teniente, F. D. D. Duran-Flores, A. M. Chapa-Oliver et al., "Oxidative and molecular responses in Capsicum annuum L. after hydrogen peroxide, salicylic acid and chitosan foliar applications," International Journal of Molecular Sciences, vol. 14, no. 5, pp. 10178-10196, 2013. 
[11] C. L. Rohwer and J. E. Erwin, "Horticultural applications of jasmonates: a review," Journal of Horticultural Science and Biotechnology, vol. 83, no. 3, pp. 283-304, 2008.

[12] K. T. Howitz and D. A. Sinclair, "Xenohormesis: sensing the chemical cues of other species," Cell, vol. 133, no. 3, pp. 387-391, 2008.

[13] N. M. A. Hassimotto, M. I. Genovese, and F. M. Lajolo, "Antioxidant activity of dietary fruits, vegetables, and commercial frozen fruit pulps," Journal of Agricultural and Food Chemistry, vol. 53, no. 8, pp. 2928-2935, 2005.

[14] N. Tierranegra-García, P. Salinas-Soto, I. Torres-Pacheco et al., "Effect of foliar salicylic acid and methyl jasmonate applications on protection against pill-bugs in lettuce plants (Lactuca sativa)," Phytoparasitica, vol. 39, no. 2, pp. 137-144, 2011.

[15] A. Cardador-Martínez, E. Castaño-Tostado, and G. LoarcaPiña, "Antimutagenic activity of natural phenolic compounds present in the common bean (Phaseolus vulgaris) against aflatoxin $\mathrm{B}_{1}$, 'Food Additives \& Contaminants, vol. 19, no. 1, pp. 62-69, 2002.

[16] A. A. Feregrino-Pérez, L. C. Berumen, G. García-Alcocer et al., "Composition and chemopreventive effect of polysaccharides from common beans (Phaseolus vulgaris L.) on azoxymethaneinduced colon cancer," Journal of Agricultural and Food Chemistry, vol. 56, no. 18, pp. 8737-8744, 2008.

[17] B. D. Oomah, A. Cardador-Martínez, and G. Loarca-Piña, "Phenolics and antioxidative activities in common beans (Phaseolus vulgaris L)," Journal of the Science of Food and Agriculture, vol. 85, no. 6, pp. 935-942, 2005.

[18] W. Brand-Williams, M. E. Cuvelier, and C. Berset, "Use of a free radical method to evaluate antioxidant activity," LWT-Food Science and Technology, vol. 28, no. 1, pp. 25-30, 1995.

[19] L. R. Fukumoto and G. Mazza, "Assessing antioxidant and prooxidant activities of phenolic compounds," Journal of Agricultural and Food Chemistry, vol. 48, no. 8, pp. 3597-3604, 2000.

[20] C. Wasternack and B. Hause, "Jasmonates and octadecanoids: signals in plant stress responses and development," Progress in Nucleic Acid Research and Molecular Biology, vol. 72, pp. 165221, 2002.

[21] B. N. Kunkel and D. M. Brooks, "Cross talk between signaling pathways in pathogen defense," Current Opinion in Plant Biology, vol. 5, no. 4, pp. 325-331, 2002.

[22] A. Vasconsuelo, A. M. Giulietti, and R. Boland, "Signal transduction events mediating chitosan stimulation of anthraquinone synthesis in Rubia tinctorum," Plant Science, vol. 166, no. 2, pp. 405-413, 2004.

[23] H. Zhang and J. Memelink, "Regulation of secondary metabolism by jasmonate hormones," in Plant-Derived Natural Products, A. E. Osbourn and V. Lanzotti, Eds., pp. 181-194, Springer, New York, NY, USA, 2009.

[24] J. Gry, L. Black, F. D. Eriksen et al., "EuroFIR-BASIS-a combined composition and biological activity database for bioactive compounds in plant-based foods," Trends in Food Science \& Technology, vol. 18, no. 8, pp. 434-444, 2007.

[25] J. M. Cheeseman, "Hydrogen peroxide and plant stress: a challenging relationship," Plant Stress, vol. 1, no. 1, pp. 4-15, 2007.

[26] Y. A. Bayoumi, "Improvement of postharvest keeping quality of white pepper fruits (Capsicum annuum, L.) by hydrogen peroxide treatment under storage conditions," Acta Biologica Szegediensis, vol. 52, no. 1, pp. 7-15, 2008.

[27] S. Pérez-Balibrea, D. A. Moreno, and C. García-Viguera, "Improving the phytochemical composition of broccoli sprouts by elicitation," Food Chemistry, vol. 129, no. 1, pp. 35-44, 2011.
[28] Y. Ruiz-García and E. Gómez-Plaza, "Elicitors: a tool for improving fruit phenolic content," Agriculture, vol. 3, no. 1, pp. 33-52, 2013.

[29] M. Serrano, P. J. Zapata, S. Castillo, F. Guillén, D. MartínezRomero, and D. Valero, "Antioxidant and nutritive constituents during sweet pepper development and ripening are enhanced by nitrophenolate treatments," Food Chemistry, vol. 118, no. 3, pp. 497-503, 2010.

[30] W.-R. Kim, E. O. Kim, K. Kang et al., "Antioxidant activity of phenolics in leaves of three red pepper (Capsicum annuum) cultivars," Journal of Agricultural and Food Chemistry, vol. 62, no. 4, pp. 850-859, 2014.

[31] M. C. Martínez-Ballesta, L. López-Pérez, M. Hernández, C. López-Berenguer, N. Fernández-García, and M. Carvajal, "Agricultural practices for enhanced human health," Phytochemistry Reviews, vol. 7, no. 2, pp. 251-260, 2008.

[32] S. N. Jimenez-Garcia, M. A. Vazquez-Cruz, R. G. GuevaraGonzalez, I. Torres-Pacheco, A. Cruz-Hernandez, and A. A. Feregrino-Perez, "Current approaches for enhanced expression of secondary metabolites as bioactive compounds in plants for agronomic and human health purposes-a review," Polish Journal of Food and Nutrition Sciences, vol. 63, no. 2, pp. 67-78, 2013.

[33] V. Raman and S. Ravi, "Effect of salicylic acid and methyl jasmonate on antioxidant systems of Haematococcus pluvialis," Acta Physiologiae Plantarum, vol. 33, no. 3, pp. 1043-1049, 2011.

[34] J. L. Guil-Guerrero, C. Martínez-Guirado, M. del Mar Rebolloso-Fuentes, and A. Carrique-Pérez, "Nutrient composition and antioxidant activity of 10 pepper (Capsicum annuun) varieties," European Food Research and Technology, vol. 224, no. 1, pp. 1-9, 2006.

[35] N. Deepa, C. Kaur, B. George, B. Singh, and H. C. Kapoor, "Antioxidant constituents in some sweet pepper (Capsicum annuum L.) genotypes during maturity," LWT-Food Science and Technology, vol. 40, no. 1, pp. 121-129, 2007.

[36] Y. Zhuang, L. Chen, L. Sun, and J. Cao, "Bioactive characteristics and antioxidant activities of nine peppers," Journal of Functional Foods, vol. 4, no. 1, pp. 331-338, 2012.

[37] E. Fernández-García, I. Carvajal-Lérida, M. Jarén-Galán, J. Garrido-Fernández, A. Pérez-Gálvez, and D. Hornero-Méndez, "Carotenoids bioavailability from foods: from plant pigments to efficient biological activities," Food Research International, vol. 46, no. 2, pp. 438-450, 2012.

[38] E. M. Yahia and J. D. J. Ornelas Paz, "Chemistry, stability, and biological actions of carotenoids," in Fruit and Vegetable Phytochemicals: Chemistry, Nutritional Value, and Stability, L. A. de la Rosa, E. Alvarez-Parrilla, and G. A. González-Aguilar, Eds., Oxford, UK, pp. 177-222, Blackwell, 2010.

[39] Y. Wahyuni, A.-R. Ballester, E. Sudarmonowati, R. J. Bino, and A. G. Bovy, "Metabolite biodiversity in pepper (Capsicum) fruits of thirty-two diverse accessions: variation in healthrelated compounds and implications for breeding," Phytochemistry, vol. 72, no. 11-12, pp. 1358-1370, 2011.

[40] G.-N. Liu, Y.-H. Zhu, and J.-G. Jiang, "The metabolomics of carotenoids in engineered cell factory," Applied Microbiology and Biotechnology, vol. 83, no. 6, pp. 989-999, 2009.

[41] J.-K. Moon and T. Shibamoto, "Antioxidant assays for plant and food components," Journal of Agricultural and Food Chemistry, vol. 57, no. 5, pp. 1655-1666, 2009.

[42] L. R. Howard, S. T. Talcott, C. H. Brenes, and B. Villalon, "Changes in phytochemical and antioxidant activity of selected 
pepper cultivars (Capsicum species) as influenced by maturity," Journal of Agricultural and Food Chemistry, vol. 48, no. 5, pp. 1713-1720, 2000.

[43] N. Deepa, C. Kaur, B. Singh, and H. C. Kapoor, "Antioxidant activity in some red sweet pepper cultivars," Journal of Food Composition and Analysis, vol. 19, no. 6-7, pp. 572-578, 2006.

[44] G. D. Kim, Y. S. Lee, J.-Y. Cho et al., "Comparison of the content of bioactive substances and the inhibitory effects against rat plasma oxidation of conventional and organic hot peppers (Capsicum annuum L.)," Journal of Agricultural and Food Chemistry, vol. 58, no. 23, pp. 12300-12306, 2010.

[45] M. Ghasemnezhad, M. Sherafati, and G. A. Payvast, "Variation in phenolic compounds, ascorbic acid and antioxidant activity of five coloured bell pepper (Capsicum annum) fruits at two different harvest times," Journal of Functional Foods, vol. 3, no. 1, pp. 44-49, 2011.

[46] P. A. Luning, R. Van Der Vuurst De Vries, D. Yuksel, T. Ebbenhorst-Seller, H. J. Wichers, and J. P. Roozen, "Combined instrumental and sensory evaluation of flavor of fresh bell peppers (Capsicum annuum) harvested at three maturation stages," Journal of Agricultural and Food Chemistry, vol. 42, no. 12, pp. 2855-2861, 1994. 

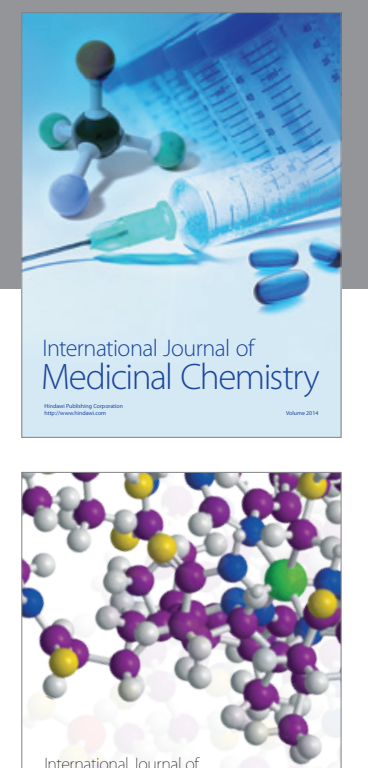

\section{Carbohydrate} Chemistry

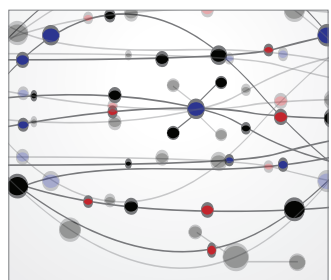

The Scientific World Journal
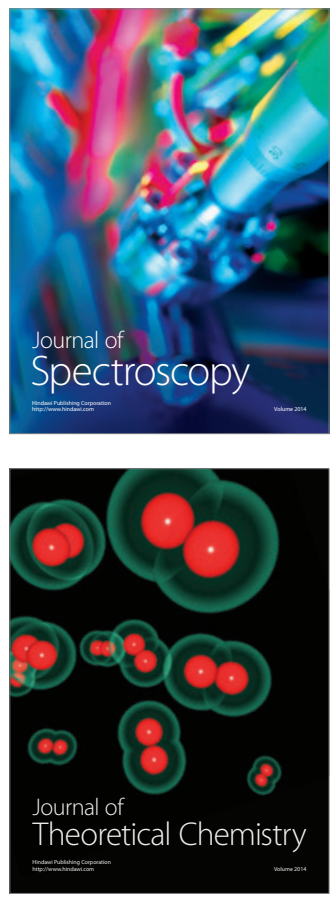
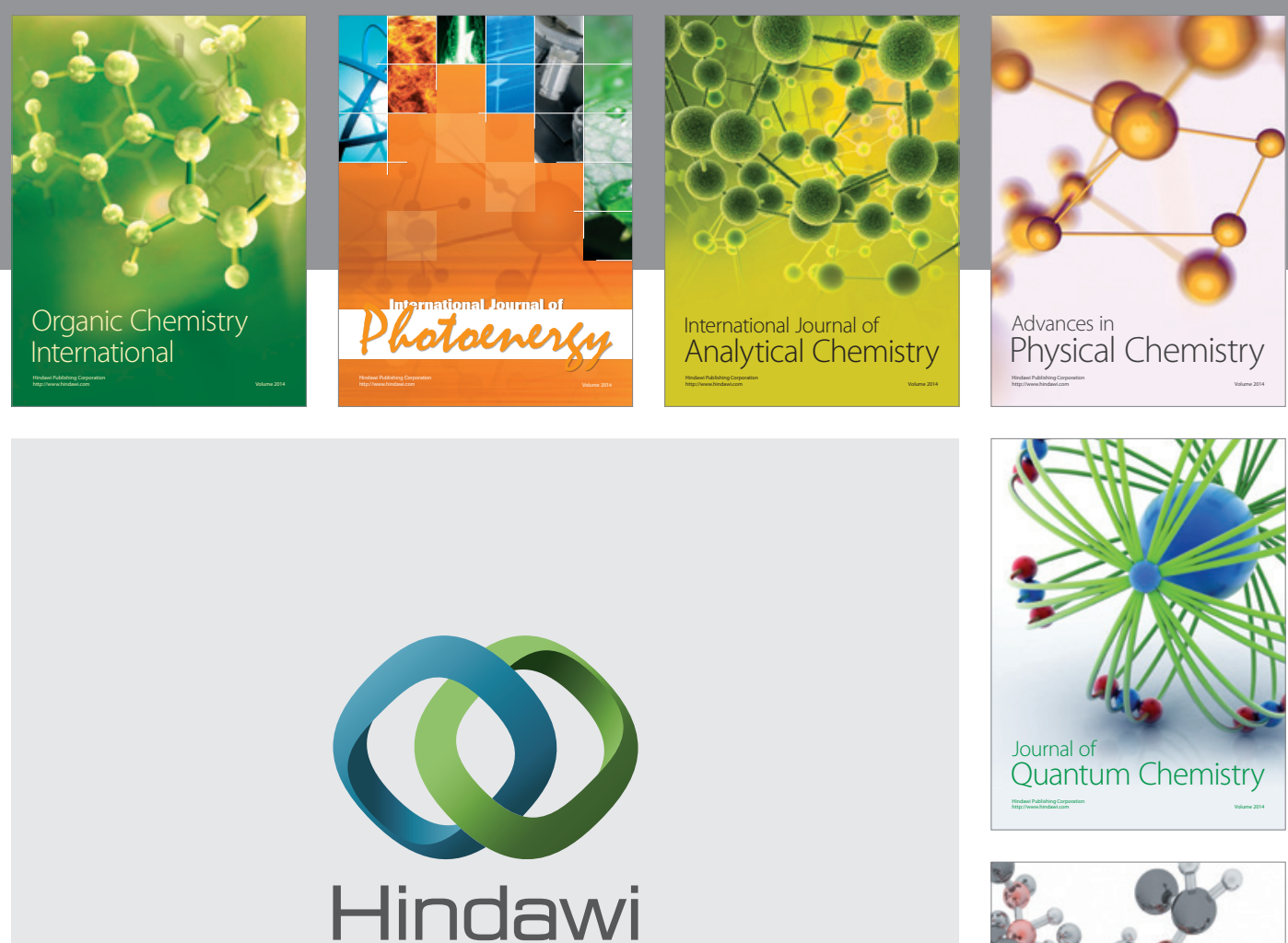

Submit your manuscripts at

http://www.hindawi.com

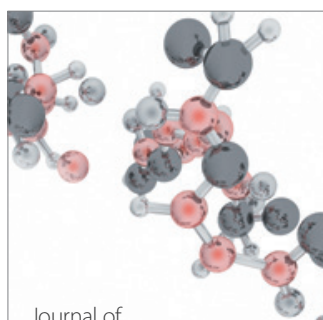

Analytical Methods

in Chemistry

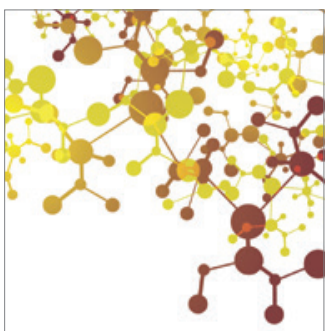

Journal of

Applied Chemistry

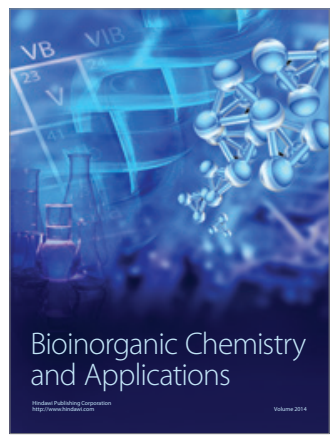

Inorganic Chemistry
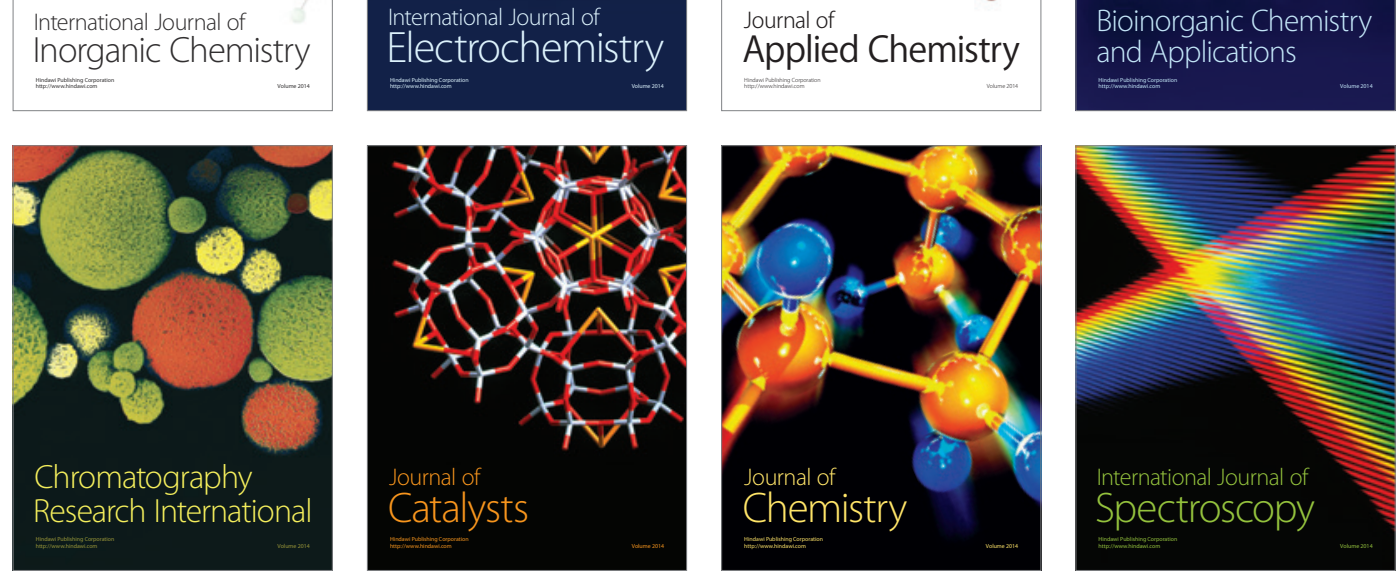